\title{
PEDIATRIC FIRST-AID: WHAT OUR CAREGIVERS KNOW ABOUT IT?
}

\section{Joana Soares ${ }^{1}$, Rita Ferreira², Pascoal Moleiro ${ }^{1}$, Rui Passadouro ${ }^{3}$ \\ 1-Serviço de Pediatria do Centro Hospitalar de Leiria; 2- Unidade de Saúde Familiar Santiago; 3- Unidade de Saúde Pública, ACES Pinhal Litoral}

\section{Background and aims:}

Accidents are an important cause of injury and death in pediatric age. Worldwide there are about 400 million of accidental injuries, responsible for more than 750 thousand of deaths.

Children are a vulnerable group-age to a number of lesions either at home or school, in sports and even in the street.

That's why caregivers knowledge about first-aid (FA) and their action in an emergent situation can be crucial to prevent a worse outcome or they can even be life-saving.

The aim of this study was to understand the knowledge of caregivers in pediatric FA in our region.

\section{Methods:}

Parents and caregivers in an outpatient service answered an inquire including socio-demographic information and 15 multiple-choice questions about 6 topics related to FA: general knowledge, accident prevention, emergency practice in the community, neurologic symptoms, trauma and toxic ingestion.

\section{Results: 187 valid inquiries}

\section{About the responders:}
政 $160 / 86 \%$
$\bar{x}$ age: $36,4 \pm 8 \mathrm{~A}$
$\bar{x}$ no children: 1,67
$\bar{x}$ no children: 1,67 (min 0; max. 8)

\section{Overall:}

Mean punctuation: 63\% (9,5 correct answers)

\section{Caregiver inquired}

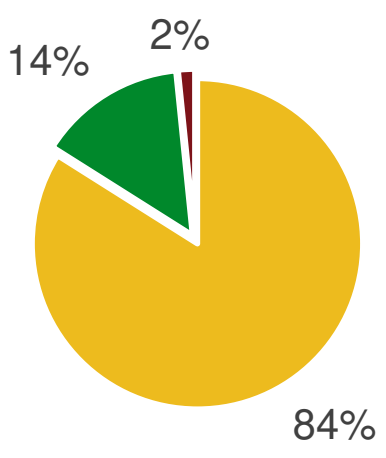

- Mother - Father -Other

\section{Occupation}

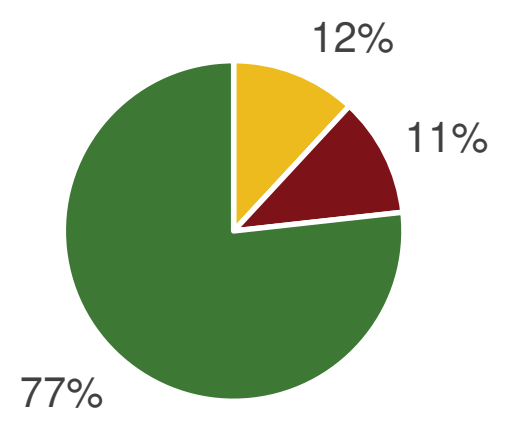

- Healthcare - Education - Other

Only 4 in 15 question had more than $75 \%$ of correct answers

\begin{tabular}{|c|c|c|}
\hline \multicolumn{2}{|c|}{ Topic } & Questions about \\
\hline General knowledge - 2 questions & Meaning of first-aid and prevention & 1,36 \\
\hline Acciddent prevention - 2 question & $\begin{array}{c}\text { Sudden infant death syndrome and } \\
\text { choking }\end{array}$ & 1,32 \\
\hline $\begin{array}{c}\text { Emergency practice in the community - } \\
\text { questions }\end{array}$ & Basic life support and drowing & 1,70 \\
\hline Neurologic symptoms - 3 questions & Syncope, head trauma and seizure & $\mathbf{1 , 9 6}$ \\
\hline Trauma - 3 questions & Wound, sprain and burns & 1,66 \\
\hline Toxic ingestion - 2 question & Poison and battery ingestion & $\mathbf{1 , 5 5}$ \\
\hline
\end{tabular}

\section{Looking for the myths}

1. First-aid is doing basic life support. (44\%)

2. In a drowning you only call for help and wait. (30\%)

3. In a choking event, you should put your finger in the child's mouth. (29\%)

4. During a seizure you should put something in the child's mouth. (16\%)

5. You should take out the tissue from the burnt skin area. $(17 \%)$

\section{Finding some of the best practices}

1. Correct approach to seizure or syncope events $(50 \%)$

2. Correct identification of head trauma warning signs. (98\%)

3. Look for immediate medical care after battery ingestion. (91\%)

4. Contact national line of intoxication after a toxic ingestion event. $(60 \%)$

\section{Conclusion:}

In our study we found an important group of people believing in wrong "first-aid" strategies based on society myths and we had poor results in accident prevention knowledge. Considering the endangerment of wrongful action in an emergency it should be implemented a FA educational program for caregivers. 